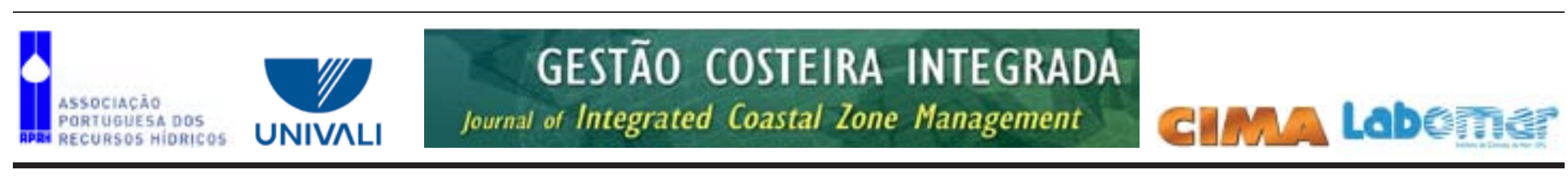

http://www.aprh.pt/rgci/pdf/rgci-399_Silva.pdf | DOI:10.5894/rgci399

\title{
Metodologia de Ensino de Educação Ambiental em Escola Situada na Área Costeira da Baía de Guanabara *
}

\section{A Teaching Methodology for Environmental Education at a School on the Shoreline of the Bay of Guanabara}

\author{
Catia Antonia da Silva ${ }^{\circledR, 1}$, Felippe Andrade Rainha ${ }^{2}$
}

\section{RESUMO}

Este artigo visa contribuir para o debate acerca do papel da educação ambiental ministrada em ambientes costeiros, e para tanto analisa as atividades pedagógicas realizadas numa escola pública do município de Sáo Gonçalo, Regiáo Metropolitana do Rio de Janeiro. Apresenta-se a metodologia que se aplicou ao ensino de educação socioambiental no projeto Cartografia da Ação e a Juventude em São Gonçalo, projeto esse que, metodologicamente atrelado à cartografia da ação, pôs dois campos científicos (a Geografia e a Sociologia) a interagirem com o fazer pedagógico (beneficiado pelos avanços a que o encaminharam as notáveis contribuiçóes de Paulo Freire). É necessário problematizar a educação ambiental, inserindo este debate na análise dos aspectos sociais das questôes de que ela trata, ou seja, na análise das formas de exclusão social presentes nas relaçôes entre a sociedade e a natureza. Cumpre também que se discutam os causadores da poluição, e se envidem esforços para construir percepçóes e sensibilidades não somente quanto à educação das novas geraçôes, mas ainda quanto às formas que a poluição assume e aos efeitos territoriais que exerce sobre o cotidiano dos moradores, especialmente nas áreas metropolitanas com acirrada competição pelo uso do solo. Buscou-se, com esta metodologia de ensino, aplicada à escola básica, alterar hábitos, construir percepçóes e estimular o trabalho coletivo. Um dos resultados do trabalho pedagógico foi que este promoveu a interação entre os saberes dos alunos, os da ciência e os dos pescadores artesanais, concorrendo para revelar problemas, atores e soluçóes. Outro resultado consistiu em os exercícios de educaçáo socioambiental reforçarem a autoestima dos alunos, notadamente dos muitos que, aparentados com pescadores, viram quanto o trabalho desses parentes seus releva não só para o sustento de famílias, como ainda para a identidade cultural do lugar. Por fim, as atividades pedagógicas também frutificaram pelo trabalho, sugerido aos alunos, de pesquisar, entrevistar e escrever acerca do espaço onde vivem, movendo-os tudo isto a gerar representaçóes em que traziam à tona e exercitavam a sua identidade cultural e os vínculos sociais que eles têm com o seu espaço vivido e concebido: a cidade de São Gonçalo e a Baía de Guanabara.

Palavras chave: Educação; Cartografia da Ação; Modernização; Poluição; Pesca Artesanal.

@ - Corresponding author

1 - Universidade do Estado do Rio Janeiro - Faculdade de Formação de Professores, Departamento de Geografia. Programa de Pós-Graduação em Geografia. Programa de Pós-Graduação em História Social. Núcleo de Pesquisa Urbano, Território e Mudanças Contemporâneas. Rua Dr. Francisco Portela, $1470-$ Patronato, CEP 24435-005, São Gonçalo, Rio de Janeiro, Brasil.e-mail: catia.antonia@gmail.com

2 - Universidade do Estado do Rio Janeiro - Faculdade de Formação de Professores, Departamento de Geografia. Programa de Pós-Graduação em Geografia. Núcleo de Pesquisa Urbano, Território e Mudanças Contemporâneas. Rua Dr. Francisco Portela, 1470 - Patronato, CEP 24435-005, São Gonçalo, Rio de Janeiro, Brasil. e-mail: felippe.rainha@gmail.com 


\section{ABSTRACT}

With the aim of contributing to the debate on how important it is to make sense of the environmental education which is delivered in coastal areas, this article examines the activities conducted at a public school in the city of Säo Gonçalo, in the Rio de Janeiro Metropolitan Region. The methodology for teaching social-environmental education is presented such as applied by a research project entitled Action Cartography and Säo Gonçalo Youth', which, methodologically related to action cartography, puts two scientific disciplines (Geography and Sociology) in interaction with pedagogical practice (as favoured by the advancements that Paulo Freire's notable contributions have led to). Environmental education needs to be problematised by bringing this debate into the analysis of social aspects of the issues which the discipline approaches, that is, into the analysis of the forms of social exclusion in the relationships between society and nature. There is also a need to discuss the causers of pollution, as well as endeavouring to help to build perceptions and sensitivities as to how new generations should be educated, the different forms that pollution assumes and the territorial consequences that it has on the everyday lives of residents, especially in metropolitan areas undergoing high land-use pressures. The teaching methodology which was applied to primary school sought to change habits, build perceptions, and encourage collective work. One of the results of the pedagogic activities was that they brought about an interaction between such types of knowledge as pupils, science and fishers bear, and that this helped to reveal problems, agents and solutions. Another result was the fact that the exercises in socio-environmental education reinforced the self-steam of pupils, especially of the many who, being related to artisanal fishers, saw how important the work of those relatives of theirs is not only for the maintenance of families but also for local cultural identity. Lastly, the pedagogic work proved fruitful also in activities, proposed to pupils, of making researches, interviews and texts about the space that they live in, all this causing them to produce representations in which they brought out and exercised their cultural identity and the social links that they have with their lived and conceived space: the city of Säo Gonçalo and the Bay of Guanabara.

Keywords: Education; Action Cartography; Modernization; Pollution; Artisanal Fisheries.

\section{INTRODUÇÁO}

Acategoria analítica orientaro presenteartigo éa educação socioambiental, a cujo respeito nele se reflexiona com base nas experiências dum trabalho de extensão universitária que, em São Gonçalo, o Núcleo de Pesquisa Urbano, Território e Mudanças Contemporâneas (NUTEMC), sediado na Faculdade de Formaçáo de Professores (FFP) da Universidade Estadual do Rio de Janeiro (UERJ), efetuou numa escola de ensino básico da rede pública, a Escola Estadual Carlos Maia.

Essa extensão universitária beneficiou-se imenso da parceria que o NUTEMC firmara com outra instituição de ensino e pesquisa, o Laboratório da Conjuntura Social: Tecnologia e Território (LASTRO), da Universidade Federal do Rio de Janeiro (UFRJ). Conjugadas, a extensão e a parceria não apenas ensejaram um rico debate teórico-metodológico sobre a educação ambiental, senão também, e é o mais importante, contribuíram a suscitar nos alunos da escola básica o pensamento crítico acerca do mundo que os rodeia. Ver-se-á abaixo como se deu este processo de construção do conhecimento.

Divide-se o artigo em três seçôes. A primeira dá sucintamente o debate teórico sobre a categoria educaçáo ambiental, e esclarece os motivos por que o NUTEMC escolheu nortear por ela a programação das atividades educacionais e a análise dos resultados da pesquisa. A segunda seção discorre as metodologias por que se pautaram as ações na escola. A seção final apresenta alguns dos resultados que a pesquisa obteve.

\section{MATERIAL E MÉTODOS}

\subsection{O moldar das ideias: início de uma discussão teórico- metodológica}

A programação das atividades que se realizariam na Escola Estadual Carlos Maia baseou-se em duas escolhas metodológicas: uma, discutir a importância de submeter o conceito de educação ambiental a um exame crítico; a outra, tentar compreender, por uma análise escalar e de totalidade, a visão de mundo dos alunos, que são crianças imersas numa realidade costeira e de periferia urbano-metropolitana.

Duas razóes tornam sumamente relevante elucidar de que modo se constrói o conceito de educaçáo ambiental: o fato de a educação ser caminho para a consciência e para a liberdade (Freire, 1979) e o debate crítico sobre o modelo de desenvolvimento e de industrialização que no Brasil se afirmou no correr do século XX (Porto-Gonçalves, 2006). Objetivou a pesquisa descobrir como a escola influi sobre a visão de mundo dos alunos, de que forma lhes modela a percepçáo do contexto socioambiental em que vivem.

A Escola Estadual Carlos Maia situa-se no município fluminense de São Gonçalo, no Bairro do Porto Velho, tendo vizinhança com uma comunidade pesqueira que se conhece localmente pelo nome de Comunidade da Esso, e que é lugar tanto de morada como de embarque e desembarque de grande número de pescadores artesanais (Figura 1). À semelhança do município do Rio de Janeiro, São Gonçalo abriga um dos maiores contingentes de pescadores artesanais da região metropolitana.

A escola e os seus alunos pertencem a uma realidade urbano-costeira com ambiente muito degradado, no qual não só se acumulam resíduos sólidos e químicos despejados pelas águas do mar, assaz poluídas no correspondente trecho da Baía de Guanabara, mas ainda se acumulam outros tantos resíduos cuja abundância, como a daqueles, resulta de longo descaso do poder público no atinente à populaçấo que esses problemas ambientais atingem com maior intensidade: falta saneamento básico, serviço regular de recolhimento de lixo, pavimentação de vias públicas e, entre mais coisas, a despoluição da baía.

Não tardaram os professores da Carlos Maia em colaborar com o projeto do NUTEMC de extensão universitária, intitulado Educação Socioambiental na Escola, com o qual também se uniu desde o começo o projeto, do LASTRO, Cartografia da Ação e a Juventude em São Gonçalo, executado 


\section{Metrópole do Rio de Janeiro segundo o número de pescadores - 2009}

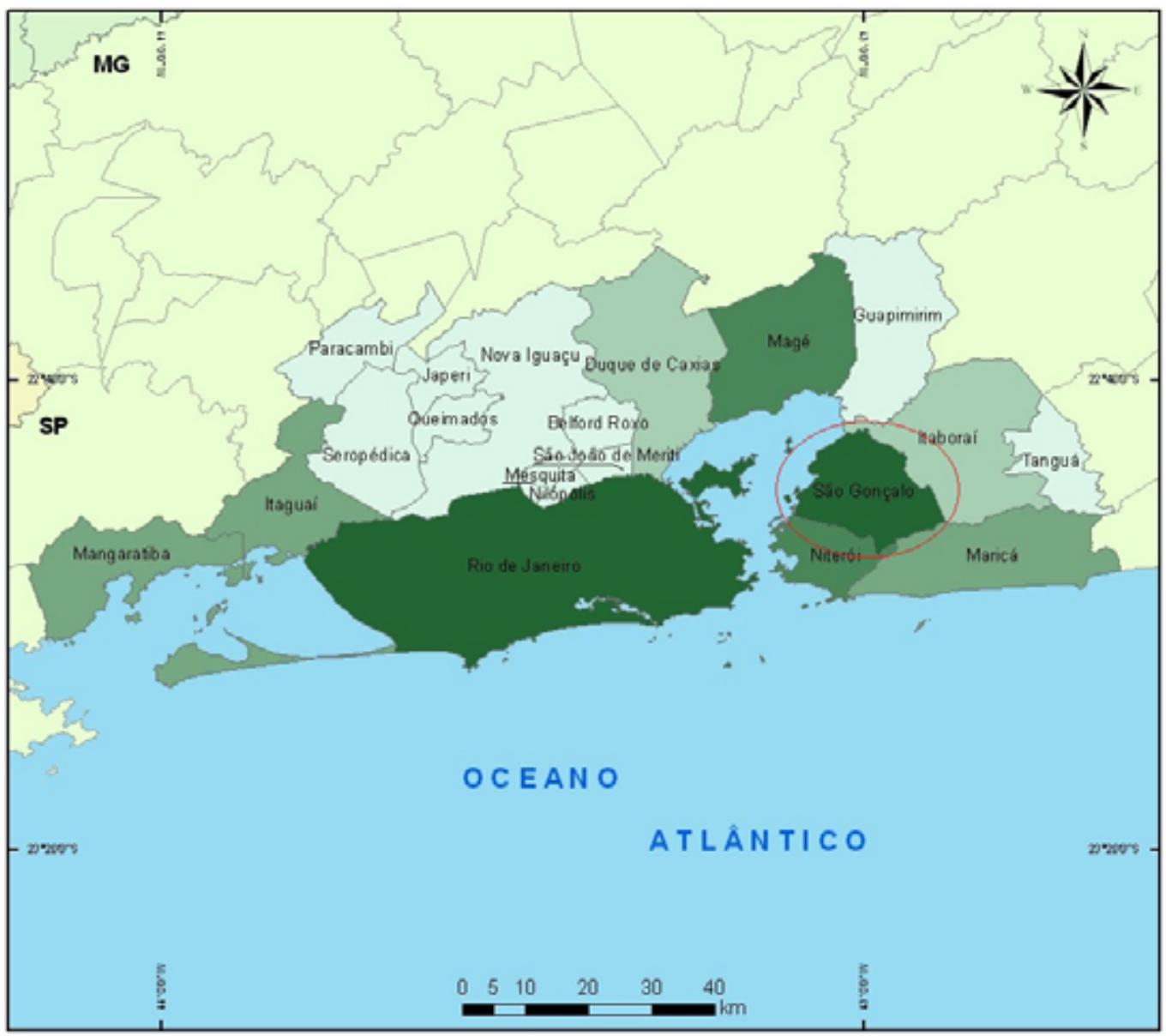

Fonte: Ministério da Pesca e Aquicultura (MPA - 2009); Grupo de Pesquisa Urbano, Território e Mudanças Contemporâneas (CNPq): Laboratório de Estudos Metropolitanos, LEME - 2011.

Figura 1. Comunidade da Esso: importante ponto em São Gonçalo para o embarque e desembarque de pescadores artesanais.

Figure 1. Esso Community: an important spot in São Gonçalo for artisanal fishers' embarking and disembarking.

sob a orientação da socióloga Ana Clara Torres Ribeiro e em parceria com o NUTEMC, onde o coordenavam a geógrafa Catia Antonia da Silva e outros professores da FFP.

O município de São Gonçalo, em cujo periférico Bairro do Porto Velho se situa a escola e residem quase todos os alunos que nela estudam, faz parte da Região Metropolitana do Rio de Janeiro (Figura 2) e, segundo o último censo do Instituto Brasileiro de Geografia e Estatística (IBGE), conta perto de 1 milhão de habitantes (Tabela 1 ) e um produto interno bruto (PIB) pouco superior a 10 bilhóes de reais. São Gonçalo tem de comum com milhares de outros municípios brasileiros esta contradição capitalista: a coexistência entre o desenvolvimento industrial, pequeno ou grande, e uma infraestrutura urbana insatisfatória, cujas instalaçóes públicas e serviços básicos geralmente são, quando existem e onde existem, de aguda precariedade.

Ao examinarem-se as questôes socioambientais da localidade tratadas na escola, tomaram-se por referência sobretudo os problemas que os pescadores artesanais vivem nesse contexto de degradação do ambiente e reestruturação econômica do espaço, reconhecendo-se que o socioespacial e o ambiental são inseparáveis entre si, e que o modelo econômico industrial e modernizador amplia a destruiçáo do ambiente e acelera a segregação social no espaço geográfico.

Além de possuir uma indústria naval consolidada, a economia do município toma parte na reestruturação produtiva da indústria fluminense, próximo que está ele ao Complexo de indústria naval e do Terminal Aquaviário da Petrobras (local de grande presença de navios e de dutos de gás e petróleo), cujas atividades econômicas influem deleteriamente na vida dos pescadores artesanais: elas tanto lhes avançam sobre antigas e valiosas áreas de pesca, havendo-os até hoje privado de muitas, quanto pela poluição lhes degradam já direta já indiretamente as áreas que sobram para eles, ou para onde os vai impelindo essa desigual porfia (Figuras 3, 4 e 5). Este o convívio entre os pescadores artesanais e os empreendimentos do grande capital na região; estas as consequências que o mesmo capital vai surtindo no ambiente. 


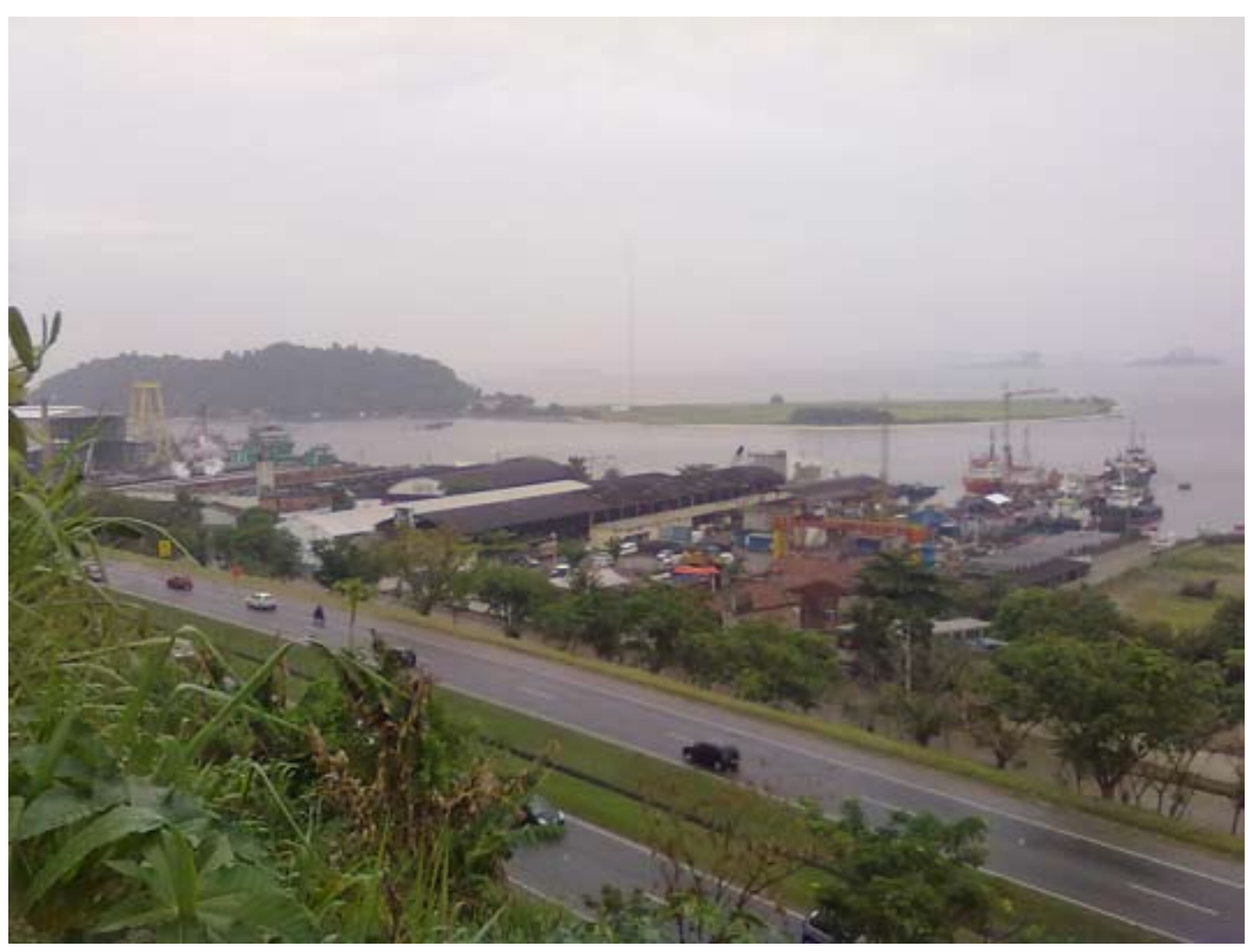

Figura 2. Região Metropolitana do Rio de Janeiro com o número total de pescadores e com a localização, em destaque, do município de São Gonçalo.

Figure 2. Rio de Janeiro Metropolitan Region featuring the total of artisanal fishers and, specially, the location of the city of São Gonçalo.

Tabela 1. Populações totais do município de São Gonçalo, da Região Metropolitana do Rio de Janeiro e do Estado do Rio de Janeiro em 2010.

Table 1. Total populations in the city of São Gonçalo, the Rio de Janeiro Metropolitan Region and the state of Rio de Janeiro in 2010.

\begin{tabular}{l|c}
\hline ÁREA & POPULAÇÃO TOTAL DA ÁREA \\
\hline São Gonçalo & 999.901 \\
\hline Região Metropolitana do Rio de Janeiro & 11.875 .063 \\
\hline Estado do Rio de Janeiro & 15.989 .929 \\
\hline
\end{tabular}

Fonte: Censo Demográfico do IBGE, 2011.

Source: IBGE Demographic Census, 2011. 


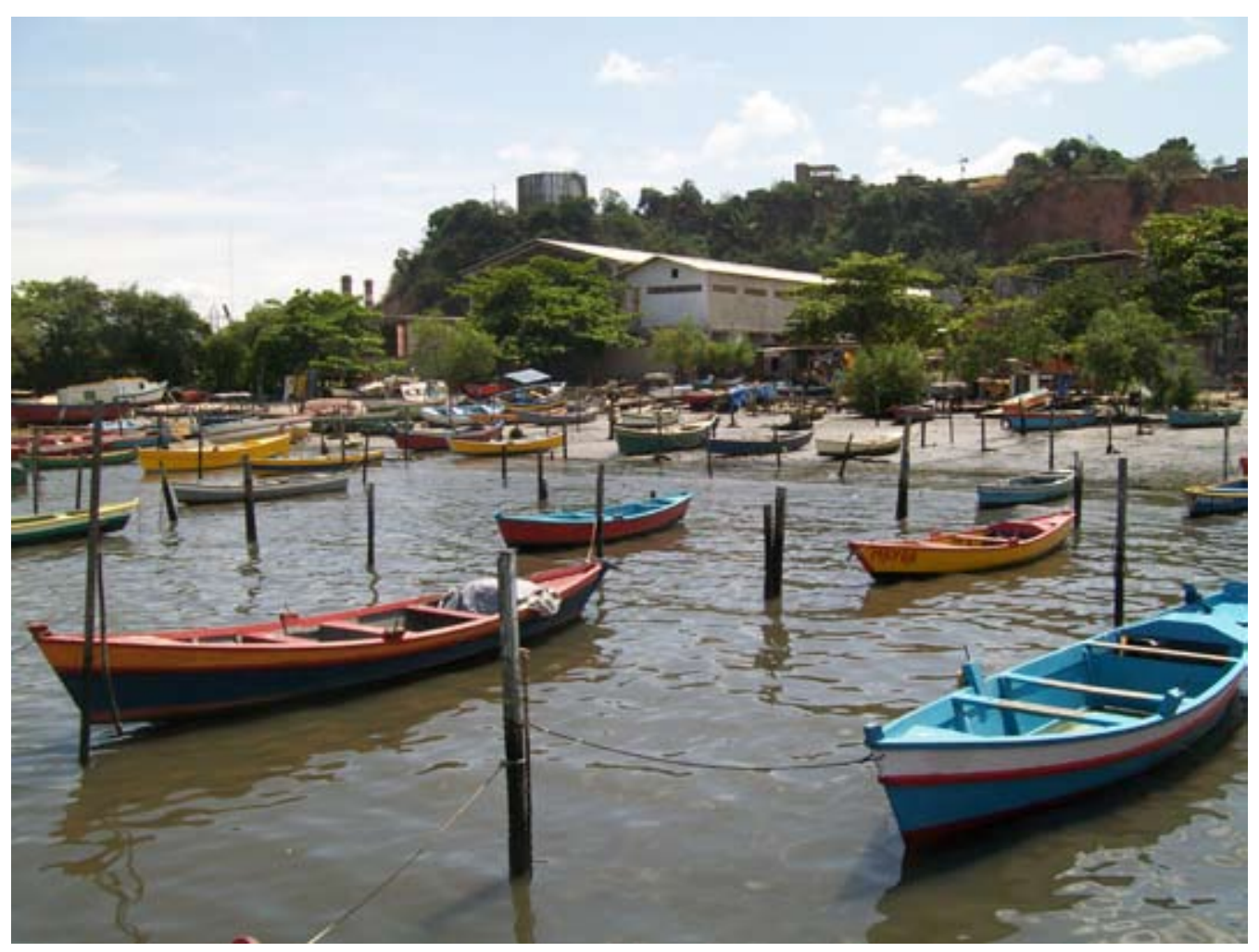

Figura 3. Sequência de estaleiros na orla do município de Sáo Gonçalo: a indústria naval ocupando praias e manguezais perto da Rodovia BR-101.

Figure 3. Row of shipyards along São Gonçalo's shoreline: the shipbuilding industry occupying shores and mangrove swamps near the BR-101 highway.

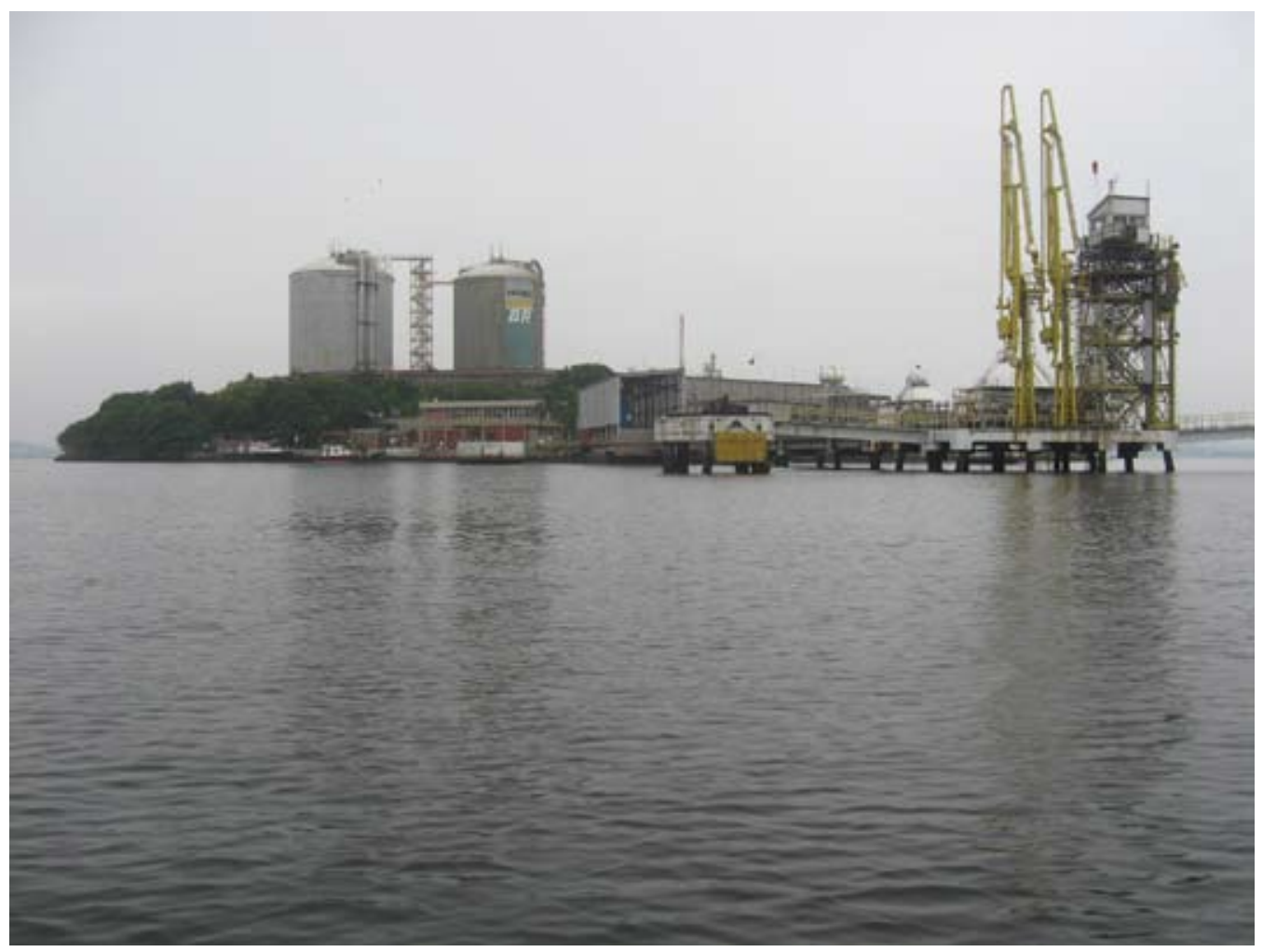

Figura 4. Terminal Aquaviário da Ilha Redonda, em São Gonçalo. Fazem-se presentes no território do município as atividades da indústria petroquímica.

Figure 4. Ilha Redonda Waterway Terminal in São Gonçalo. Petrochemical industry activities have a noticeable presence in the city's territory. 
Assim entra em cena a educação ambiental, para elucidar os nexos entre a ação humana e o meio, e infundir quanto às questôes ambientais uma consciência social mais profunda, que ajude a minorar, a longo prazo, os efeitos danosos surtidos no espaço pela modernização. Compreender a ação humana é, neste sentido, desvendar os agentes produtores de tal modelo modernizante com que se tem acerbado a já forte segregaçáo socioespacial das periferias, onde às dificuldades socioeconômicas decorrentes dos salários baixos se aliam os males que vêm com a poluição, com a precariedade dos serviços de saúde, e com a falta de instalações públicas adequadas e de equipamentos culturais.

Isto posto, não tem cabida idealizar abstrata $\mathrm{e}$ romanticamente a educação ambiental, mas sim concebêla própria a desvendar ao educando os elos da cadeia de poder nas questóes ambientais e a dinâmica da relação entre a sociedade, o Estado, a economia e o meio. Impende compreender os modelos de modernizaçáo e de industrialização que impuseram como paradigma o uso dos recursos naturais, qual se estes fossem inesgotáveis e talhados sobretudo para um modelo de produção de mercadorias em larga escala animado pela construção social de necessidades, ou seja, o modelo de produção duma sociedade de consumo de massa (Porto-Gonçalves, 2006).

$\mathrm{Na}$ escola muitos exercícios guiaram-se pelo conceito de Tavares (2011: 50) de educação cidadã: "[...] ao relacionar infância, alfabetização e cidade, visando à complexificação do que seja alfabetização na contemporaneidade, estamos defendendo que a cidade é como um livro de espaços, onde os diferentes textos, imagens, mensagens, corpos, fluxos se hibridizam, configurando uma poderosa midia, cujos significados atravessam o sujeito citadino, exigindo outras formas de percepção, leitura, alfabetizaçâo."

Adverte Tavares (2011) em que, para entender a educação popular, é necessário construir o conhecimento baseando-se no modo de ver dos alunos, nas suas trajetórias de vida, nas suas percepçóes da realidade, nas suas visões de mundo e nas suas vozes; é preciso interagir com o lugar vivido e com a cidade desigual.

Em 2010, no início da execução do projeto na Escola Estadual Carlos Maia, realizou-se entre os alunos um censo com o fim de saber quantos tinham ligação com a pesca. Das 226 crianças matriculadas, 112 responderam ao questionário, e apurou-se que: cerca de $35 \%$ delas eram parentes de algum pescador (pai, tio, avó, entre outros), $40 \%$ haviam-se já servido de um barco como transporte ou para pescarem, e 25\% conheciam bem a linguagem e os petrechos específicos da pesca (entre estes os tipos de embarcação, de rede, de traineira, etc.). Assim, trabalhou-se a construção do conceito de educaçáo socioambiental com as turmas do $4^{\circ} \mathrm{e}$ $5^{\circ}$ anos do ensino básico, no que se tomaram por referência as discussóes da equipe executora do projeto. Também muito relevou a participação dos pescadores artesanais, a palestrarem com os alunos, num intercâmbio de perguntas e respostas que promoveu a interação dos saberes (científicos, populares e vividos) e facultou compreender mais a fundo os

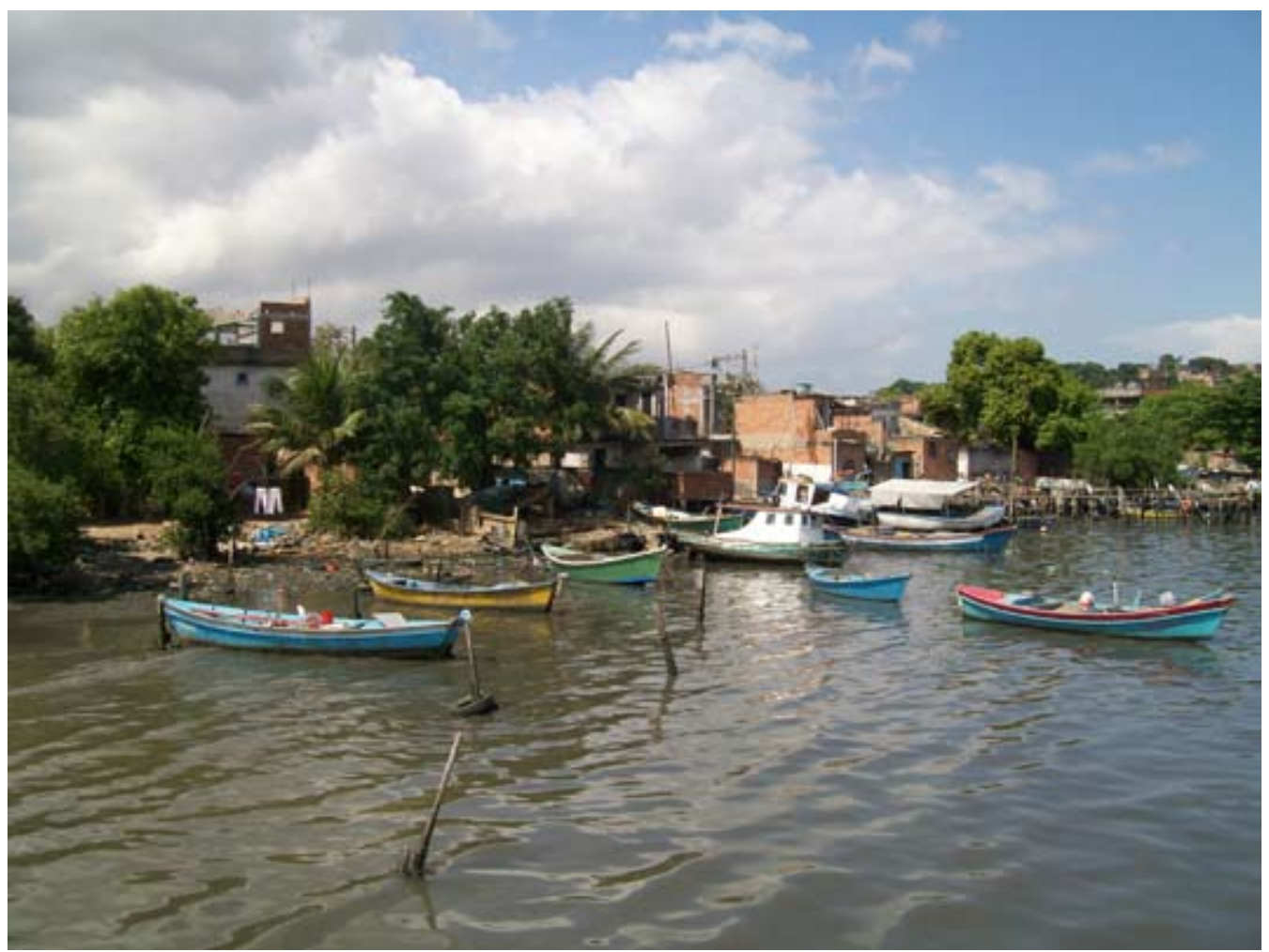

Figura 5. Comunidade do Gradim: outro importante ponto de embarque e desembarque de pescadores artesanais no município de São Gonçalo.

Figure 5. Gradim community: another important spot in São Gonçalo for artisanal fishers' embarking and disembarking. 
problemas da modernização industrial e as consequências da poluição para a vida dos pescadores.

Em tal diálogo entre os saberes, discerniram-se dois fatores que influem para a degradação da Baía de Guanabara: um, a incúria do Estado, a qual deixa grassar os problemas de que se inçam a precariedade do saneamento básico e a míngua de fiscalização das atividades potencialmente poluidoras; o outro fator, o grande capital, cujos empreendimentos na região, de ordinário voltados para a indústria petrolífera, envolvem atividades que de maneira direta concorrem para degradar ainda mais o ambiente. Além disso, apresentaram-se as formas como se organizam, como reivindicam, protestam e lutam socialmente os habitantes e pescadores que vivem todos os dias os problemas citados.

O trabalho pedagógico utilizou o conceito de cartografia da ação, formulado por Ribeiro et al. (2001). Fundouse metodologicamente nesse conceito o exercício de as crianças fazerem mapas, nos quais elas reconheciam as açóes, representando por símbolos os pontos em que se localizavam os pescadores, os problemas ambientais, as áreas de protestos, o poder público e as barqueatas. Mormente em certas atividades práticas, o uso da cartografia da ação facultou uma aprendizagem mais autônoma, assim como livre de discursos preestabelecidos e dos existentes nos textos didáticos (Silva, 2011).

Segundo Ribeiro et al. (2001), a cartografia da ação social é aquela que pode compreender e representar o movimento da sociedade, das lutas e dos novos desejos, das açóes e desejos das bases populares. É a cartografia da ação que representa também o cotidiano da vida coletiva: "A cartografia aqui sugerida é a da denúncia e também aquela que orienta a ação social, desvendando contextos e antecipando atos (Almeida, 1994). Significa, portanto, tanto a contextualização veloz da ação hegemônica, cada vez mais estrategicamente localista, quanto a valorização imaginativa dos lugares vividos, onde a vida escorre ou ganha força reflexiva e transformadora. Como carta, o mapa não aparece como instrumento isolado ou como bela ilustração de textos, exacerbando critérios estéticos, mas sim como ferramenta analitica e como sustento da memória dos outros. Neste sentido, propóe-se uma cartografia incompleta que se faz, fazendo. Uma cartografia praticada, que não seja apenas dos usos do espaço, mas também utilizável, de forma que ocorra a sincronia espaço-temporal, o que apoiaria, inclusive, o trabalho interdisciplinar." (Ribeiro et al., 2001, p.43)

Portanto, a cartografia da ação é a não oficial, que se ocupa com as trajetórias das bases populares, com os itinerários de lutas e de protestos, com as rotas de trabalho no cotidiano, com as manifestaçóes da cultura, com as normas ocultas não estatais da sociedade. Pode-se com esta orientação desvendar um novo mundo, desvelar o invisível, deparar beleza no anônimo e potencial no inconsiderado, surpreender riquezas naquilo e naqueles que são reputados como pobres de tudo. Esta concepção afina-se com a de Santos (1996) sobre os homens lentos, com a de Freire (1979) acerca do compromisso humano, o compromisso de reflexáo e de consciência em face das contradiçôes e anelos que fragmentam o espaço e lhe infundem a segregação.

À luz deste humanismo concreto, a cartografia da açáo social pode ser considerada uma categoria a um tempo analítica e metodológica, já que permite experimentar a construção de novos mapeamentos e símbolos, originários do contexto de um espaço vivido e concebido, portadores de novas formas de representação e de novos projetos, de novos sentidos de ação de sujeitos a quem se julga por comuns, banais. Cumpre manter o espírito aberto para ver as novas possibilidades de redesenhar o mundo, de cada um reescrever a sua própria história, de reescrever-se a história das bases populares (Santos, 1996; Santos et al., 2000).

Neste mundo impregnado de segregação, observa-se que os mais afligidos pelos grandes danos ambientais são as classes populares. Por isso revela-se demasiado simples o conceito de educação ambiental. E isto, em primeiro lugar porque, em grande parte, quem inflige ao meio sérios danos com resíduos tóxicos (líquidos, sólidos, orgânicos, inorgânicos, etc.) não é o homem ou a mulher que vivem na pobreza, mas o vigente modelo de industrialização, o modelo de desenvolvimento que se serve da natureza vendo-a como recurso. Não basta só dizer aos alunos que "não joguem o copinho de plástico no Imboassu [rio de São Gonçalo], porque vai para a Baía de Guanabara", pois limitar-se a essa recomendação significa reproduzir um discurso superficial, falto de teor crítico. A ideia do exercício pedagógico realizado é esclarecer aos alunos que o copinho plástico descartável pertence a um modelo hegemônico de industrialização, modelo esse que pouco se importa com o paradeiro final do copinho, por muito que se saiba que este levará cerca de 100 anos para decompor-se na Baía de Guanabara. Deve-se mostrar aos alunos o fato de os principais agentes poluidores da baía (que são o Estado e o grande capital) impingirem aos consumidores, que totalizam milhóes na Região Metropolitana do Rio de Janeiro, a responsabilidade pelo destino final dessa mercadoria, agora chamada lixo.

O conceito da categoria analítica educação socioambiental utilizado nas atividades pedagógicas, os pesquisadores construíram-no baseando-se principalmente nos trabalhos de campo que realizaram junto aos pescadores artesanais da Baía de Guanabara, esta território de múltiplos agentes a operarem em múltiplas escalas (do mundo, do país e do município) e a gerarem conflitos sem conta. Esses trabalhos de campo deram a conhecer que os pescadores usavam como vias de passagem diversos rios que, no decurso do processo de urbanização, se haviam transformado em esgotos (por exemplo, o Rio Imboassu, em São Gonçalo, e o Canal de Magé, no município de Magé). Também se descobriu que, a par da Comunidade da Esso, havia outros pontos gonçalenses de embarque e desembarque da pesca artesanal: o Gradim, a Praia das Pedrinhas, Itaoca e a Praia da Luz.

Depois de entrevistarem pescadores artesanais, passaram os alunos e os professores a compreender-lhes as dificuldades, persuadindo-se do muito que descabe cultivar uma visão romântica da educação ambiental e crer seja suficiente "plantar uma árvore". Para esses pescadores, a natureza é a sua morada, o seu trabalho e a sua vida. A poluição vinda com o grande capital e as restrições impostas pelas leis marítimas e ambientais fazem-lhes conduzir as suas pequenas embarcaçóes para áreas cada vez mais distantes daquelas onde originalmente pescavam, para além da Ponte RioNiterói os impulsam, em direção à desembocadura da Baía de Guanabara, premidos pela necessidade de obter pescados melhores e em maior número que os que essas circunstâncias 
mais e mais desfavoráveis deixam restar-lhes. Mas todo esse esforço dos pescadores artesanais para compensarem as suas perdas os penaliza vivamente, expondo-os por muito mais horas aos rigores do sol, à extenuação do trabalho e às ameaças naturais que lhes rondam a vida na atividade em mar alto.

A educação ambiental é, pois, uma categoria analítica que permite compreender o espaço, tanto o rural como o urbano, onde a destruição do ambiente implica a destruição das camadas sociais menos favorecidas. Por isso não se pode analisar a questão ambiental isoladamente, sob pena de tornar essa categoria ideologizante ao invés de esclarecedora nestes espaços-tempos de globalização e de sociedade de consumo.

A seguir, discorre-se a metodologia empregada na atividade que se levou a efeito na escola.

\subsection{A prática metodológica e resultados preliminares}

As atividades na Escola Estadual Carlos Maia ocorreram nos anos letivos de 2010 e 2011, englobando quatro turmas do primeiro ciclo do ensino fundamental: duas da terceira série (quarto ano) e duas da quarta série (quinto ano), constituídas de crianças de nove a doze anos de idade. Realizaram-se dezesseis oficinas, seis no primeiro e dez no segundo ano do projeto. O objetivo metodológico do ensino era integrar os saberes científicos dos pesquisadores universitários, os saberes empíricos dos pescadores artesanais, os saberes transmitidos por notícias jornalísticas e os que as crianças obtinham pela sua experiência com a cidade e com a baía.

As notícias jornalísticas provieram de recortes dos jornais de maior circulação no município, e versavam sobre casos de poluição comuns ocorridos nele e na Baía de Guanabara, destacando-se os relativos a: enchentes; derramamento de óleo; acúmulo de resíduos sólidos; falta de saneamento básico; e reivindicaçóes e lutas dos pescadores artesanais diante dos processos de modernização que reduzem as áreas de pesca.

Com base nos recortes de jornal e nos problemas referidos pelos alunos, criou-se um glossário, que traz conceitos fundamentais e um quadro elucidativo dos problemas, dos sujeitos da ação social, das formas de reivindicação e da busca de soluções. Assim também, organizou-se um banco de dados com este material e com aquilo que se apurou no levantamento de dados nacionais e internacionais sobre a poluição de ambientes costeiros, as consequências dessa poluição e os conflitos sociais decorrentes dela. É necessário que se analise a questâo ambiental, correlacionando-se as diversas escalas em que se dá ela: a da globalização, a nacional, a metropolitana e a do lugar (a escala do espaço vivido e concebido: a cidade, o bairro, a relação entre o mar e a terra).

Além disso, uma vez que os alunos manifestaram o desejo de entrevistar os pescadores artesanais que vivem no município de São Gonçalo e pescam na Baía de Guanabara, o grupo de pesquisa orientou-os na preparação de uma série de perguntas que elas fariam a um desses pescadores. Eis o questionário:

Lista das perguntas ao pescador artesanal, preparada pelos alunos no âmbito da aula na Escola Estadual Carlos Maia em São Gonçalo/RJ:
1. Há quanto tempo você pesca? Aprendeu com quem?

2. Você gosta deste trabalho? Por quê?

3. Você mora perto da Baía de Guanabara?

4. O que você acha da pesca na Baía de Guanabara?

5. Como foi o derramamento de óleo?

6. Por que os navios despejam muito óleo?

7. Há quanto tempo você pesca na Baía de Guanabara?

8. Por que os peixes estão morrendo na Baía de Guanabara?

9. Quais são os problemas de poluição na Baia de Guanabara?

No dia da entrevista, a qual se efetuou em sala de aula, as crianças prepararam o material e fizeram as perguntas. Tomou-se a providência, metodologicamente recomendável, de registrar tudo, usando-se gravadores, câmeras fotográficas e filmadoras, para produzir destarte um material que, após ser devidamente organizado, ficaria à disposiçáo de todos os envolvidos no trabalho (alunos, professores e pesquisadores), para que ulteriormente o pudessem analisar e depois divulgá-lo.

A entrevista e a exposição dos dados serviram de base para encontros posteriores, em que, por exemplo, se elaborou um quadro de problemas ambientais segundo os percebiam os alunos, e criaram-se mapas coletivos (mapas que eles elaboraram trabalhando em conjunto e com a atenção voltada para temas-problema). A referência foi o novo quadro temático (Tabela 2), em que se reuniram as problemáticas aventadas durante a execução do projeto, tais como as consequências da poluiçáo da Baía de Guanabara e o papel das barqueatas na luta em defesa do ambiente.

Concebeu-se esta atividade como preparaçáo para a última, com o que se objetivou ajudar os alunos a perceber as formas que a ação social pode assumir e as maneiras como os agentes se servem do território. Ao mesmo tempo, tencionouse estimular a consciência crítica e propositora dos alunos, elemento central para a formaçáo de um pensamento gestor apto a perceber as condiçóes do presente e a necessidade de mudanças futuras, e assim os alunos formularam possíveis açóes que contribuiriam a prevenir a degradação ambiental da Baía de Guanabara. Concluído o trabalho da oficina, perguntou-se-lhes: "Agora que vocês sabem que têm o poder de reivindicar o que quiserem, o que fariam para mudar a atual situação da Baía de Guanabara? Citem pelo menos três açôes que você fariam. " Dessa reflexão resultou a Tabela 2.

\section{RESULTADOS E DISCUSSÃO}

Aqui, expóem-se brevemente os resultados que as atividades produziram.

Quanto às entrevistas, perceberam os alunos, os professores e os pesquisadores a relevância da oralidade do pescador, o qual, trabalhador das águas, conhece de perto aquilo que os moradores urbanos, estranhos a elas, não veem. Nas águas da Baía de Guanabara, os pescadores observam grande quantidade de lixo flutuante e lixo imerso, o que robora conclusóes a que anteriormente chegou a análise de Ferreira et al. (2011). Os pescadores também relataram, por um lado, que essa alta quantidade de lixo lhes destrói as redes de pesca e, por outro lado, que desde o derramamento petrolífero ocorrido no ano 2000 há no fundo da baía um enorme 
acúmulo de óleo. Eles igualmente comentaram a abundância de navios de grande porte que circulam pela baía: navios indo ou vindo do Porto do Rio de Janeiro, ou dos terminais aquaviários da Ilha Redonda e da Ilha Comprida.

Contaram como receberam, por tradição de família, a cultura da pesca, um saber que em geral se transmite oralmente de pais a filhos, e referiram as suas memórias sobre os espaços em que hoje convivem com sérios problemas ambientais: eram espaços pouco ocupados, onde rareavam embarcaçōes e inexistiam aterros. Os pescadores falaram sobre o seu percurso cotidiano de casa para o trabalho e do trabalho para casa, e expuseram o seu saber empírico acerca do tempo e do clima, revelando-se grandes conhecedores dos ventos, do mar e de outros domínios da natureza. Os alunos entusiasmaram-se, sentiram-se sujeitos dos debates e aprenderam muito com o que disserem os pescadores.

Essas entrevistas deram elementos para o exercício, nas oficinas seguintes, de reconhecer os principais problemas e de cogitar soluçóes (Tabela 2).

No concernente à prática da cartografia da ação social, o objetivo maior foi o exercício pedagógico da confecção coletiva do mapa: cada turma, depois de elaborar a Tabela 2 , eleger o tema do mapa e criar a legenda, passou para a etapa de produzir o mapa. Também se atribuiu aos alunos a função de organizar esta etapa do trabalho. Aos mapas produzidos chamou-se de mapas das açôes.

$\mathrm{Na}$ etapa de elaborá-los, incumbiu-se a um aluno a tarefa de escrever a legenda e demais elementos, a outros alunos a de criar os símbolos da legenda escolhidos pela turma, e a outros ainda a organizaçáo da atividade de descobrir os pontos onde colar as figurinhas (símbolos da legenda).

Quanto ao debate sobre a questáo ambiental e ao exercício de representar espacialmente os fenômenos sociais e do ambiente, cabe observar que, mais do que para entender

Tabela 2. Propostas dos alunos usadas na elaboração dos "mapas das açóes”.

Table 2. Pupils' suggestions used to prepare the 'maps of actions'.

\begin{tabular}{|c|c|}
\hline PROPOSTA DOS ALUNOS & $\begin{array}{l}\text { No DE ALUNOS QUE } \\
\text { AVENTARAM A PROPOSTA }\end{array}$ \\
\hline $\begin{array}{l}\text { Denunciar aos órgãos competentes (Ministério Público, Defensoria Pública } \\
\text { e outras instituiçōes do Poder Judiciário) os responsáveis pelas açōes } \\
\text { poluidoras. }\end{array}$ & 6 \\
\hline Limpar a Baía de Guanabara. & 10 \\
\hline Protestar contra a poluição juntamente com os pescadores artesanais. & 10 \\
\hline $\begin{array}{l}\text { Realizar campanha local, pedindo aos moradores que não vazem lixo nos } \\
\text { logradouros públicos. }\end{array}$ & 2 \\
\hline Divulgar na localidade o slogan 'Não Poluir a Baía de Guanabara'. & 17 \\
\hline Zelar pela natureza (evitando causar poluição, plantando árvores, etc.). & 8 \\
\hline Evitar o desmatamento e as queimadas. & 5 \\
\hline $\begin{array}{l}\text { Realizar campanha local, pedindo aos moradores que não vazem lixo na Baía } \\
\text { de Guanabara. }\end{array}$ & 3 \\
\hline Não verter lixo no chão da escola nem do bairro. & 10 \\
\hline $\begin{array}{l}\text { Queixar-se à prefeitura, ou fazer protestos contra ela, denunciando a falta } \\
\text { frequente de coleta de lixo. }\end{array}$ & 3 \\
\hline $\begin{array}{l}\text { Conscientizar a toda a população da necessidade de limpar a Baía de } \\
\text { Guanabara. }\end{array}$ & 1 \\
\hline Evitar o derramamento de óleo nas águas da Baía de Guanabara. & 5 \\
\hline Participar de protestos contra a poluição da Baía de Guanabara. & 6 \\
\hline Acabar com a atividade petrolífera na Baía de Guanabara. & 3 \\
\hline Melhorar a infraestrutura urbana, principalmente a rede de esgotos. & 5 \\
\hline Demandar em juízo a Petróleo Brasileiro S.A. (Petrobras). & 4 \\
\hline Acabar com o lixão (vazadouro de lixo a céu aberto) de São Gonçalo. & 1 \\
\hline $\begin{array}{l}\text { Entrevistar os moradores para saber o que pensam da poluição na Baía de } \\
\text { Guanabara. }\end{array}$ & 1 \\
\hline
\end{tabular}


a gênese dos problemas ambientais da Baía de Guanabara e representá-los num mapa, o trabalho foi importante para se construiu com os alunos, coletivamente, uma consciência ambiental alicerçada na ação, uma açáo cuja ideia de movimento dos sujeitos no espaço e de atribuiçóes e intuitos desses sujeitos (no caso a prefeitura, as empresas e os pescadores) é indispensável para que se desvendem as relaçôes de produção e de poder que regem o território, se rompa com o cotidiano (tantas vezes alienado) e se concretize a mudança. Os alunos consideraram que, para se resolverem os problemas do município, cumpre que se executem, com prioridade, estas açóes: prover o recolhimento regular do lixo nas vias públicas e na baía, demandar em juízo as empresas poluidoras, apoiar ativamente os protestos em defesa da Baía de Guanabara, e os próprios alunos absterem-se de deitar lixo às vias públicas. O papel da educação socioambiental é contribuir para a consciência crítica do indivíduo e seu grupo, neste caso a conscientizaçấo dos alunos acerca, por exemplo, das condições de vida precárias dos pescadores relacionadas com a poluição crescente da Baía de Guanabara e com a resultante míngua do pescado.

Noutra oficina, intitulada Natureza e Pesca Artesanal: uma parceria de sucesso, foram notáveis as reivindicaçóes que os alunos sugeriram dirigir à prefeitura de São Gonçalo, no tocante aos problemas urbano-ambientais do município, evidenciados em fotografia e manchetes de jornais. Os alunos sensibilizaram-se bastante com certa fotografia que se exibiu no decorrer da oficina, e mostrava uma ave toda coberta com o negror do óleo vazado de um oleoduto que estende sob as águas da Baía de Guanabara. Mas todos os materiais apresentados nesta oficina contribuíram por estimular a reflexão dos problemas causados pelos diversos tipos de poluição que assolam o território da baía, assim como dos agentes responsáveis seja pela causa, seja pela fiscalização do problema.

A última oficina realizou-se no dia 14 de outubro de 2011, no auditório da Faculdade de Formaçáo de Professores da Universidade do Estado do Rio de Janeiro (UERJ/FFP), quando 125 crianças participaram, com seus professores e familiares, numa atividade especial, que foi a exposição de todo o que durante a execuçáo do projeto os alunos haviam produzido. Este evento contou igualmente com a participaçáo de pescadores artesanais, pesquisadores da UERJ e estudantes de diversos cursos de graduação da FFP.

Grandes protagonistas desde o início do projeto, os alunos entraram no campus erguendo alto uma faixa em que pediam a atenção de todos para os problemas vivenciados cotidianamente na Baía de Guanabara. E os mesmos alunos, depois de apresentarem os seus mapas das açōes, encenaram uma breve representação teatral em que denunciavam os problemas da baía (Figura 6).

Tudo isto foi um exercício dialógico que deu vida e sentido à educaçáo ambiental, mostrando o nexo entre o homem e a natureza, entre a desigualdade social e as afliçóes causadas pela destruição do ambiente, a qual é sobre as classes pobres que as mais das vezes lança $\mathrm{o}$ amargor dos seus efeitos. E não são apenas os desastres ambientais, é mais ainda a experiência diária, o cotidiano vivido sob a opressáo do mau cheiro, da

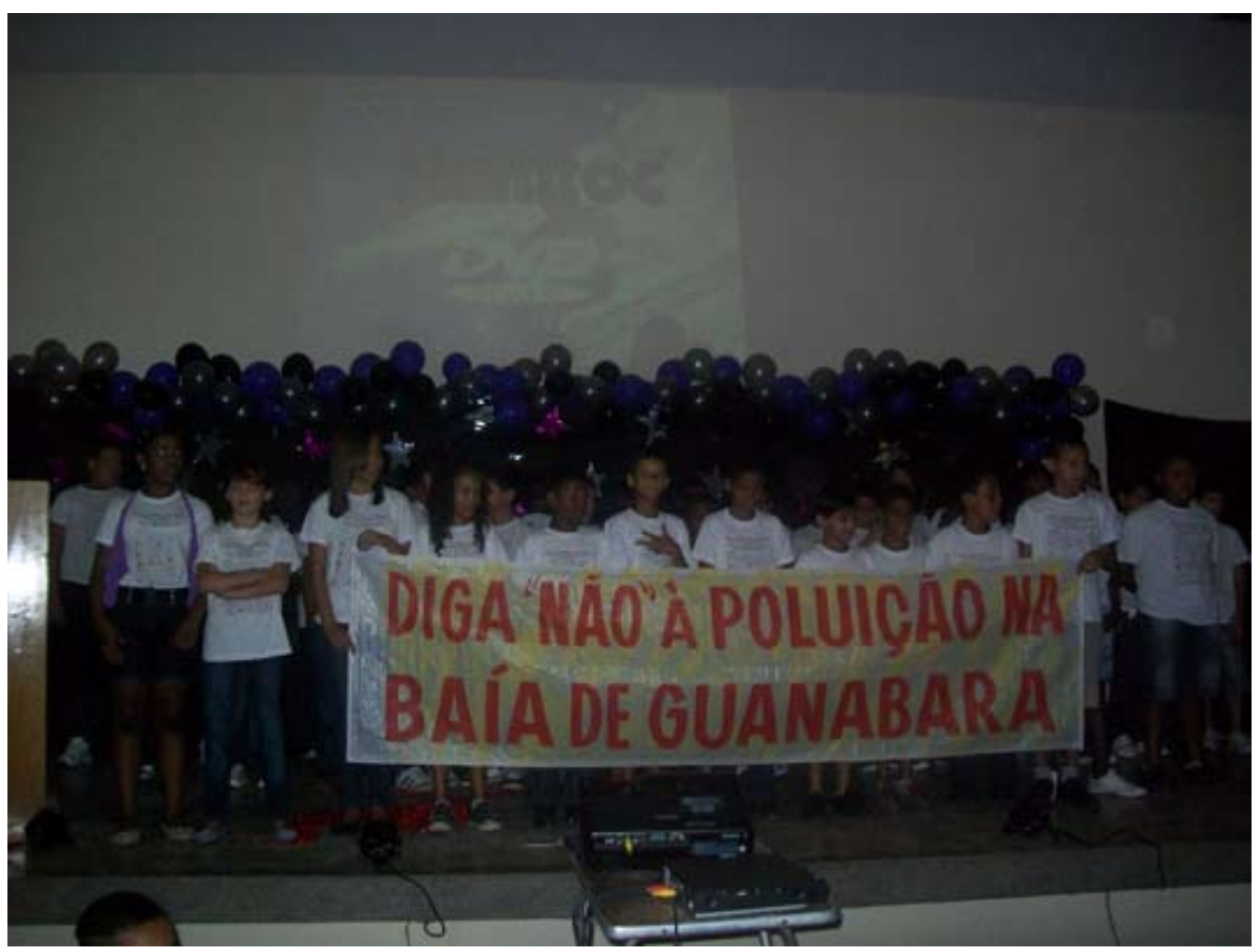

Figura 6. Atividade final: os alunos envolvidos no projeto protestam durante o evento na UERJ/FFP. Figure 6. Final activity: pupils involved in the project protest during the event at the UERJ/FFP. 'SAY "NO" TO THE POLLUTION OF THE BAY OF GUANABARA!'. 
contaminação química e bacteriana, da baixa autoestima a que a diuturnidade destas circunstâncias penosas costuma arrastar o espírito, enquanto ajuda, com os largos traços da precariedade, a desenhar as fronteiras reais e imaginárias que delimitam os espaços subjetivos do território.

A participação das crianças não só lhes estimulou a expressão verbal e a capacidade de exprimirem as suas angústias, mas também ensejou que elas se exercitassem como sujeitos pensadores, capazes de formular as suas questóes e de exprimir a sua perplexidade. As crianças romperam barreiras simbólicas, transpuseram fronteiras sociais, entre estas a representada pelo fato de nunca antes haverem entrado no campus São Gonçalo, da Universidade do Estado do Rio de Janeiro. Os pais, tomados de emoção, fotografavam a faculdade e, pondo-a no plano de fundo, fotografavam-se a si mesmos.

A educação socioambiental tem de ser humanista, precisa formar novas geraçóes de pensadores e gestores críticos, novas geraçóes de pessoas que lutem pela dignidade humana, pela proteção da natureza e pela possibilidade de conceber um desenvolvimento que não gere a infrene destruição das faunas e floras, não exproprie os territórios e não instaure a crise na sociedade (crise de valores, de ética, das instituiçóes sociais, do sentido de estar no mundo).

\section{CONCLUSÓES}

Para avaliar devidamente o papel que há de ter a educação ambiental, cumpre persuadir-se da indissociabilidade entre o homem e o meio. Ao destruir-se a natureza em nome do desenvolvimento, destroem-se também os grupos sociais pobres, como o dos pescadores artesanais; destrói-se a cultura e identidade desses grupos; destrói-se-lhes o sentido de estar no mundo.

Embora concorram para a produção de alimentos e geração de empregos nas inúmeras cidades em que residem e atuam, os pescadores artesanais são trabalhadores invisíveis para essas mesmas cidades, que os ignoram solenemente, como os ignoram os meios de comunicação, onde eles muito raro têm voz. Daí serem de fundamental importância o trabalho de campo nas localidades pesqueiras e as entrevistas com pescadores. A metodologia da educação socioambiental relaciona saberes locais e científicos com as informaçóes que os meios de comunicação difundem quanto às açóes do Estado e das empresas. O objetivo é compreender os processos e as suas consequências socioespaciais, bem como analisar os desígnios e os discursos dos vários agentes.

Refletir acerca da gestão costeira, julgando-a como instrumento para intervir sobre a realidade, deve-se entender que é uma forma de ação social, uma ação em que o trabalho pedagógico com as novas geraçóes se apresenta como uma das etapas necessárias. Valorizar os saberes locais e os dos pescadores contribui para a visibilidade social de pontos da Baía de Guanabara dos quais a população e até mesmo as pesquisas não tomavam conhecimento.

Com este artigo pretende-se oferecer aos professores de outras escolas um método pedagógico em que eles se possam basear, a adaptarem-no, é claro, ao contexto e história delas. O método salienta a importância de determinados procedimentos em que o projeto exercitou os alunos:
1) Relacionar as questóes sociais com as do ambiente, aclarando os aspectos políticos de ambos os grupos de questóes e os projetos em favor dos quais se porfia no território.

2) Examinar criticamente os contextos sociais, econômicos e culturais em que os projetos de modernização e de desenvolvimento geram cada vez maior segregação socioespacial.

3) Mediante exercícios de redação e de desenho, atividades lúdicas e de confecção de mapas, e até palestras, como as dos pescadores artesanais, perceber como a escola se insere no contexto do bairro e da cidade, percepção que é fundamental para formar sujeitos de direitos (sujeitos capazes de agir em busca de cidadania).

4) Mapear as suas próprias trajetórias, localizando no mapa os pontos de poluição, as ações do poder público e os direitos e deveres dos cidadãos.

5) Conhecer as leis ambientais, os direitos sociais, as funçôes do poder público, os movimentos sociais e as lideranças e reivindicaçóes desses movimentos.

6) Realizar atividades lúdicas (desenhos, pinturas, peças de teatro), representando no espaço cênico as questóes sociais e ambientais.

7) Correlacionar várias disciplinas e conteúdos programáticos (a Geografia, a Sociologia, a História, a Biologia, a Arte), trabalhando os temas vividos e propostos pelas turmas em consonância com o projeto coletivo elaborado pelos professores ou pela escola durante o ano letivo.

\section{REFERÊNCIAS BIBLIOGRÁFICAS}

Ferreira, J. de A.; Silva, C.A. da; Resende, A.T. (2011) Projeto Baía Limpa: Monitoração de Ambientes Marinhos Degredados por Resíduos Sólidos na Baía de Guanabara, Rio de Janeiro, Brasil. Revista da Gestão Costeira Integrada, 11(1):103-113. DOI: 10.5894/rgci202

Freire, P. (1979) - Educação e mudança. 78p., Editora Paz e Terra, São Paulo, SP, Brasil. ISBN: 857753170-8.

IBGE (2011) - Sinopse do Censo Demográfico 2010. s/.p., Instituto Brasileiro de Geografia e Estatística (IBGE), Rio de Janeiro, RJ, Brasil. ISBN: 978-8524041877. Disponível em http://www.ibge.gov.br/home/estatistica/ populacao/censo2010/sinopse.pdf

Porto-Gonçalves. C.W. (2006) - A globalização da natureza e a natureza da globalizaçâo. 461p., Editora Civilização Brasileira, Rio de Janeiro, RJ, Brasil. ISBN: 852000683-3.

Ribeiro, A.C.T.; Barreto, A.R.S.; Lourenço, A.; Costa, L.M. de C.; Amaral, L.C.P. do (2001) - Por uma cartografia da ação: pequeno ensaio de método. Cadernos IPPUR (ISSN: 0103-1988), ano XV(2) / Ano XVI(1): 33-52, Rio de Janeiro, RJ, Brasil. Disponível em https://docs.google. com/file/d/0By1DYFPclamKTWtaR0ZKdmNTQ0E/ edit

Santos, M.; Bernardes, A.; Zerbini, A.; Gomes, C.; Bicudo, E.; Almeida E.; Contel, F. B.; Grimm, F.; Nobre, G.; Antongiovanni L.; Pinheiro, M.B.; Xavier, M.; Silveira, M. L.; Montenegro, M.; Rocha, M.F. da; Arroyo, M.; Borin, P.; Ramos, S.; Belo, V. de L. (2000) - O papel ativo da Geografia: um manifesto. 18p. XII Encontro Nacional de Geógrafos, Florianópolis, SC, Brasil. 
Santos, M. (1996) - A natureza do Espaço: técnica e tempo, razão e emoção. 308p., Editora HUCITEC, São Paulo, SP, Brasil. ISBN: 853140713-3.

Silva, C.A. (org.). (2011) - Educação Socioambiental na escola: algumas experiências do cotidiano à luz da metodologia de ensino da Cartografia da Ação Social. 80p., Editora Consequência, Rio de Janeiro, RJ, Brasil. ISBN: 9788564433021 .
Tavares, M.T.G. (2011) - Os pequenos e a cidade: a cidade de São Gonçalo como livro de espaços. In: C.A. da Silva, A.C.T. Ribeiro \& A. Campos (org.), Cartografia da Ação e movimentos da sociedade: desafios de método e experiências urbanas, pp. 83-97, Editora Lamparina, Rio de Janeiro, RJ, Brasil. ISBN: 9788598271897. 